\title{
Risk-based Prioritization among Air Pollution Control Strategies in the Yangtze River Delta, China
}

\section{Citation}

Zhou, Ying, Joshua S. Fu, Guoshun Zhuang, and Jonathan I. Levy. 2010. Risk-based Prioritization among Air Pollution Control Strategies in the Yangtze River Delta, China. Environmental Health Perspectives 118(9): 1204-1210.

\section{Published Version}

doi://10.1289/ehp.1001991

\section{Permanent link}

http://nrs.harvard.edu/urn-3:HUL.InstRepos:8605288

\section{Terms of Use}

This article was downloaded from Harvard University's DASH repository, and is made available under the terms and conditions applicable to Other Posted Material, as set forth at http:// nrs.harvard.edu/urn-3:HUL.InstRepos:dash.current.terms-of-use\#LAA

\section{Share Your Story}

The Harvard community has made this article openly available.

Please share how this access benefits you. Submit a story.

\section{Accessibility}




\title{
Risk-Based Prioritization among Air Pollution Control Strategies in the Yangtze River Delta, China
}

\author{
Ying Zhou, ${ }^{1,2}$ Joshua S. Fu, ${ }^{3}$ Guoshun Zhuang, ${ }^{4}$ and Jonathan I. Levy ${ }^{2}$ \\ ${ }^{1}$ Department of Environmental and Occupational Health, Rollins School of Public Health, Emory University, Atlanta, Georgia, USA; \\ ${ }^{2}$ Department of Environmental Health, Harvard School of Public Health, Boston, Massachusetts, USA; ${ }^{3}$ Department of Civil and \\ Environmental Engineering, University of Tennessee, Knoxville, Tennessee, USA; ${ }^{4}$ Department of Environmental Science and \\ Engineering, Fudan University, Shanghai, People's Republic of China
}

Background: The Yangtze River Delta (YRD) in China is a densely populated region with recent dramatic increases in energy consumption and atmospheric emissions.

ОвJестіVEs: We studied how different emission sectors influence population exposures and the corresponding health risks, to inform air pollution control strategy design.

Methods: We applied the Community Multiscale Air Quality (CMAQ) Modeling System to model the marginal contribution to baseline concentrations from different sectors. We focused on nitrogen oxide $\left(\mathrm{NO}_{\mathrm{x}}\right)$ control while considering other pollutants that affect fine particulate matter [aerodynamic diameter $\leq 2.5 \mu \mathrm{m}\left(\mathrm{PM}_{2.5}\right)$ ] and ozone concentrations. We developed concentration-response (C-R) functions for $\mathrm{PM}_{2.5}$ and ozone mortality for China to evaluate the anticipated health benefits.

RESULTS: In the YRD, health benefits per ton of emission reductions varied significantly across pollutants, with reductions of primary $\mathrm{PM}_{2.5}$ from the industry sector and mobile sources showing the greatest benefits of 0.1 fewer deaths per year per ton of emission reduction. Combining estimates of health benefits per ton with potential emission reductions, the greatest mortality reduction of 12,000 fewer deaths per year [95\% confidence interval (CI), 1,200-24,000] was associated with controlling primary $\mathrm{PM}_{2.5}$ emissions from the industry sector and reducing sulfur dioxide $\left(\mathrm{SO}_{2}\right)$ from the power sector, respectively. Benefits were lower for reducing $\mathrm{NO}_{\mathrm{x}}$ emissions given lower consequent reductions in the formation of secondary $\mathrm{PM}_{2.5}$ (compared with $\mathrm{SO}_{2}$ ) and increases in ozone concentrations that would result in the YRD.

ConCLUSIONS: Although uncertainties related to C-R functions are significant, the estimated health benefits of emission reductions in the YRD are substantial, especially for sectors and pollutants with both higher health benefits per unit emission reductions and large potential for emission reductions.

KeY wORDS: air pollution, China, CMAQ, health risk, ozone, $\mathrm{PM}_{2.5}$, Yangtze River Delta. Environ Health Perspect 118:1204-1210 (2010). doi:10.1289/ehp.1001991 [Online 17 May 2010]

The Yangtze River Delta (YRD), which generally refers to southern Jiangsu Province, eastern and northern Zhejiang Province, and the municipality of Shanghai, is the fastest growing economic development region in China and one of the most densely populated regions in the world. Shanghai is one of the world's largest cities, with $>18$ million long-term residents and a population density of $>40,000$ people $/ \mathrm{km}^{2}$ in some districts. Accompanying this economic development has been a dramatic increase in energy consumption and air pollution emissions. For example, although the Shanghai metropolitan area and the provinces of Jiangsu and Zhejiang constitute only $2 \%$ of the area of China, their emissions of sulfur dioxide $\left(\mathrm{SO}_{2}\right)$, nitrogen oxides $\left(\mathrm{NO}_{\mathrm{x}}\right)$, and fine particulate matter [aerodynamic diameter $\left.\leq 2.5 \mu \mathrm{m}\left(\mathrm{PM}_{2.5}\right)\right]$ accounted for $12 \%, 15 \%$, and $12 \%$, respectively, of total emissions in China in 2006, which increased by $36 \%, 55 \%$, and $14 \%$, respectively, from 2001 to 2006 (Zhang et al. 2009). $\mathrm{NO}_{\mathrm{x}}$ emissions are of particular concern because they have increased the fastest and are forecasted to increase even more (Chen et al. 2006).

Several studies (Kan et al. 2004; Li et al. 2004; Streets et al. 1999) have evaluated the health benefits of air pollution control in Shanghai, primarily $\mathrm{SO}_{2}$ and $\mathrm{PM}_{10}$, and occasionally sulfate particles. Similar studies have been conducted in other parts of China, attributable to air pollution in the Pearl River Delta (Loh et al. 2008). In another study in the Pearl River Delta area, Wang et al. (2005) investigated how the emissions from different sectors influenced the concentrations of gaseous pollutants including ozone. And Wang and Mauzerall (2006) quantified the total health damages from PM due to anthropogenic emissions from Zaozhuang, Shangdong Province. Besides these studies on regional air pollution, both the magnitude of the air pollution problem in China at the national level and the contribution from the power plants have been estimated by several studies, including one of the first to quantify the national burden of air pollution (World Bank 1997). In another study, Wang and Smith (1999) focused on the electric power sector in the context of determining the secondary benefits of greenhouse gas reductions. In addition, a large-scale study conducted (Ho and Nielsen 2007) assessed the health damages of air pollution in China and examined several pollution control policies and how they might affect economic performance. such as a recent estimate of annual deaths
Researchers have pointed out that emission reductions in different sectors may have different levels of effectiveness on reducing human exposure (Li et al. 2004; Streets et al. 1999) and that the benefits of many pollution control measures likely far exceed the costs; however, the variance by sector and its policy implications for future pollution control have not been investigated systematically in China. For example, none of the previous studies included both ozone and $\mathrm{PM}_{2.5}$ in assessing the health damages, although exposures have been associated with increased mortality and a variety of other health outcomes (Bell et al. 2006, 2007; Levy et al. 2005; Pope and Dockery 2006). The exclusion of ozone is partly because of past emphasis on the power sector, where $\mathrm{SO}_{2}$ and PM receive greater attention, but is also attributable to limitations in the atmospheric models used in previous studies ( $\mathrm{Li}$ et al. 2004). Also, most studies used $\mathrm{PM}_{10}$ and total suspended particles (TSPs) to estimate population exposure to PM in China, whereas epidemiologic studies in the United States and worldwide have demonstrated more robust associations with $\mathrm{PM}_{2.5}$.

Our study will fill this gap by comparing how emission control strategies across different sectors (e.g., power generation, mobile sources, industry) influence population exposures and health risks related to $\mathrm{PM}_{2.5}$ and ozone in the YRD area. The sectoral details will help guide development strategies that are economically and environmentally optimal, providing the basis for policy makers to determine how to

Address correspondence to Y. Zhou, Emory University, Rollins School of Public Health, Department of Environmental and Occupational Health, 1518 Clifton Rd. NE, Atlanta, GA 30322 USA. Telephone: (404) 712-9583. Fax: (404) 7278744. E-mail: ying.zhou@emory.edu

Supplemental Material is available online (doi:10.1289/ehp.1001991 via http://dx.doi.org/).

We thank M. Hu, C. Chen, K. He, Y. Gao, Y. Liu, and J. Vargo for valuable input. We also thank the National Institute for Computational Sciences at the University of Tennessee for providing CPU time on the Kraken supercomputer to conduct the air quality simulations.

This study was sponsored by the Energy Foundation (grant G-0901-10653).

Any opinions, findings, and conclusions expressed in this material are those of the authors.

The authors declare they have no actual or potential competing financial interests.

Received 22 January 2010; accepted 15 May 2010. 
prioritize future control efforts among the different sectors in the YRD.

\section{Materials and Methods}

In this study, we applied air pollution health impact assessment methods, following approaches articulated elsewhere (National Research Council 2002; World Health Organization 2000). Briefly, this entailed estimating baseline emissions and the marginal contribution from individual source categories, use of a chemistry-transport model to characterize population exposures associated with source category emissions, and application of concentration-response (C-R) functions from the epidemiological literature along with characterization of population patterns to quantify health impacts.

CMAQ modeling and emission inventory. A state-of-the-science Eulerian grid modelthe Community Multiscale Air Quality (CMAQ) modeling system [version 4.6; U.S. Environmental Protection Agency (EPA), Research Triangle Park, NC, USA] was applied to an emission inventory we developed to estimate the baseline concentrations as well as the marginal concentration change associated with hypothetical control strategies for multiple sectors in the YRD. CMAQ has capabilities to simulate the various chemical and physical processes important for understanding atmospheric processes and thus allowed us to model population exposure to pollutants such as ozone and $\mathrm{PM}_{2.5}$. Although CMAQ is currently used in analyses in the United States (Cohan et al. 2007) and in some air quality assessments in China (Fu et al. 2009), it has rarely been used for risk assessments in China and other developing countries. We applied a three-way nested model with $27-\mathrm{km}$ (covering all of China), 9-km (covering eastern China), and 3-km (covering the YRD) grid resolutions, respectively [see Supplemental Material, Figure S1 (doi:10.1289/ehp.1001991)]. Outputs from the $27-\mathrm{km}$ and $9-\mathrm{km}$ domains were used as boundary conditions for the $3-\mathrm{km}$ domain. To develop meteorological inputs for CMAQ, we used the fifth-generation mesoscale model (MM5) developed by the U.S. National Center for Atmospheric Research. For more detailed information on CMAQ and MM5 configurations, see Supplemental Material, Table S1.

The emission inventory for the YRD consisted of emissions mainly from four sectors: power plants, industrial sources (e.g., metallurgical, mineral, cement, chemical industries, small industries such as coke and brick production), mobile sources, and domestic life (e.g., livestock, residential, and biomass burning). Power plants and emissions from production processes of major industrial sources were modeled as point sources. Mobile sources mainly included on-road vehicle emissions in the major cities. Emissions from domestic life and the fugitive emissions from industry were modeled as area sources.

In developing our emission inventory, we used the Asian emission inventory for 2006 that was developed for the INTEX-B project of the U.S. National Aeronautics and Space Administration (Zhang et al. 2009). The resolution of the INTEX-B emission inventory is $30 \mathrm{~min} \times 30 \mathrm{~min}(-55 \mathrm{~km} \times-55 \mathrm{~km})$. To capture finer resolution within our emission inventory, we incorporated various sources of input, using collaborations with local agencies, Google Earth (version 5.1.3535.3218; Google Inc., Mountain View, CA, USA) to identify the locations of large point sources based on their addresses, updated road networks and LandScan population data to characterize the distribution of mobile source emissions, and the statistical yearbook of the major cities in the YRD for domestic fuel emissions from the consumption of coal, liquified petroleum gas, coal gas, and natural gas.

After conducting the base-case simulation using CMAQ, we validated it using available monitoring data for ozone and $\mathrm{PM}_{2.5}$ collected in Shanghai before proceeding with additional model runs. Because $\mathrm{PM}_{2.5}$ is not currently a criteria air pollutant in China and there are no publicly available ozone monitoring data, the monitoring data we had access to for model validation were all from research monitoring sites located in Shanghai and operated by Fudan University [see Supplemental Material, Figure S2 (doi:10.1289/ehp.1001991)]. Hourly ozone monitoring data were available from three stations for 4 weeks (2-9 May, 12-19 June, 10-17 July, and 14-21 August 2006). Daily average $\mathrm{PM}_{2.5}$ monitoring data were available from one station for 1-29 April, 1-26 August, and 1-28 November 2006.

Once the validation of the baseline run was satisfactory, we designed scenarios to model the marginal contribution of selected emission sectors in the YRD to the baseline concentrations in the $3-\mathrm{km}$ resolution domain. Although some underestimation of the total health benefits would have resulted, given the significant regional transport of $\mathrm{PM}_{2.5}$ and ozone, the size of the $3-\mathrm{km}$ domain provides YRD environmental authorities with the most relevant information for control strategy prioritization and decision making.

For this study, we modeled sectoral impacts in total (e.g., all power plants in the YRD simultaneously). Table 1 lists the emission reduction scenarios in more detail. In designing the scenarios, we considered several factors. First, we focused on $\mathrm{NO}_{\mathrm{x}}$ emission control, a stated interest of decision makers and a pollutant for which emissions have been increasing the fastest in recent years among the pollutants modeled (Zhang et al. 2009). Second, because $\mathrm{NO}_{\mathrm{x}}$ emissions influence $\mathrm{PM}_{2.5}$ and ozone concentrations, and given the anticipated health impacts of $\mathrm{PM}_{2.5}$ and ozone, we also considered other pollutants [e.g., $\mathrm{SO}_{2}$, volatile organic compounds (VOCs), and primary $\mathrm{PM}_{2.5}$ ] that can affect $\mathrm{PM}_{2.5}$ and ozone concentrations. Lastly, we tried to cover the current and proposed pollution control measures by the Shanghai government in preparation for World Expo 2010 (Chen CH, personal communication), although these scenarios do not necessarily correspond to specific official control measures. In each of the four major sectors (power, industry, mobile, and domestic), we included scenarios for reducing $\mathrm{NO}_{\mathrm{x}}$ alone (scenarios 1, 3, 7, and 10) and scenarios for reducing $\mathrm{NO}_{\mathrm{x}}$ along with other pollutants to evaluate the relative magnitude of impacts (scenarios 2, 5, and 9). We also considered scenarios for reducing VOC alone (scenarios 4 and 8), allowing for analyses of interactions between $\mathrm{NO}_{\mathrm{x}}$ and VOC controls, as well as one scenario (scenario 6) to check for nonlinearity of concentration changes to the magnitude of emission reductions. The magnitude of the emission reductions corresponds with specific control technologies for the power sector and an approximation of technologically and financially plausible emission reductions in other sectors, although the logistical feasibility and costs of controls clearly vary across sectors.

In each case, we estimated the total exposure and public health impacts but focused on the marginal impacts per ton of emissions, allowing for direct comparisons among sectors. Although CMAQ calculates speciated $\mathrm{PM}_{2.5}$ concentrations, we report the total $\mathrm{PM}_{2.5}$ concentrations in calculating the population

Table 1. CMAO simulation scenarios targeting $\mathrm{NO}_{\mathrm{x}}$ and other pollutant emission reductions in different sectors.

\begin{tabular}{lllc}
\hline Scenario & Sector & \multicolumn{1}{c}{ Pollutants reduced } & Reduction \\
\hline 1 & Power & $\mathrm{NO}_{x}$ alone $(\mathrm{SCR}$ alone) & $85 \%$ \\
2 & Power & $\mathrm{NO}_{x}+\mathrm{SO}_{2}$ (SCR $\left.+\mathrm{FGD}\right)$ & $85 \%$ for $\mathrm{NO}_{x}+90 \%$ for $\mathrm{SO}_{2}$ \\
3 & Mobile & $\mathrm{NO}_{x}$ alone & $20 \%$ \\
4 & Mobile & $\mathrm{VOC}_{\text {alone }}$ & $20 \%$ \\
5 & Mobile & $\mathrm{NO}_{x}+\mathrm{VOC}+\mathrm{PM}$ & $20 \%$ \\
6 & Mobile & $\mathrm{NO}_{x}+\mathrm{VOC}+\mathrm{PM}$ & $50 \%$ \\
7 & Industry & $\mathrm{NO}_{x}$ alone & $20 \%$ \\
8 & Industry & $\mathrm{VOC}_{\text {alone }}$ & $20 \%$ \\
9 & Industry & $\mathrm{NO}_{x}+\mathrm{VOC}+\mathrm{PM}$ & $20 \%$ \\
10 & Domestic & $\mathrm{NO}_{x}$ alone & $20 \%$ \\
\hline
\end{tabular}

Abbreviations: FGD, fluidized gas desulfurization; SCR, selective catalytic reduction. 
exposure under different scenarios, which includes changes in multiple constituents. To estimate the pollutant-specific benefits, we used the incremental population exposure change between scenarios. For example, the difference in population exposure between scenario 1 and the base-case allowed us to calculate exposure reductions associated with $\mathrm{NO}_{\mathrm{x}}$ emissions, whereas the difference between scenarios 2 and 1 allowed us to approximate the exposure reductions associated with $\mathrm{SO}_{2}$ emissions.

Population data. To calculate the population exposure and subsequent health impacts, we collected population data from two different sources. First, we used LandScan 2007 as the primary basis for estimating exposures. LandScan is a worldwide population database compiled on a 30-second $\times 30$-second latitude/ longitude grid. Census counts (at subnational level) were apportioned to each grid cell based on likelihood coefficients, which are based on proximity to roads, slope, land cover, nighttime lights, and other information (Dobson et al. 2000; Oak Ridge National Laboratory 2009). Similar to Census data, LandScan provides a single population estimate for each location, although these estimates include diurnal movements and collective travel habits, whereas most censuses count people at their nighttime residences. In addition, LandScan includes annual updating of data inputs, as well as global coverage, which potentially allows for easy comparisons with other parts of the world in the future.

However, LandScan does not provide the same level of detail as Census data in terms of population demographics, so we obtained additional information necessary for subsequent calculation of health benefits (e.g., baseline mortality rates) from China Census 2000 (China Data Center 2003). To calculate the health benefits, we applied spatially variable baseline mortality rates, to reflect the fact that the YRD area includes both urban and rural areas and that their residents may have different disease patterns, socioeconomic status, and life expectancy. For counties in the YRD, the average baseline mortality rate is $0.6 \%$, with the 5 th and 95 th percentile rate at $0.34 \%$ and $0.84 \%$, respectively. We assumed these estimates based on Census 2000 are applicable to population estimates from LandScan 2007 data.

Population exposure. The population exposure change under different scenarios was calculated by combining population in each location with the corresponding concentration change. Geographical information system (ArcGIS) software (version 9.3; ESRI, Redlands, CA, USA) was used to convert population data to match the grid structure of CMAQ. Because the emissions of different pollutants under study vary significantly by sector, we focused our analyses on the marginal benefits per ton of emission reductions. We facilitated these comparisons by using the concept of intake fraction (iF), the fraction of a material released from a source that is inhaled or ingested (Bennett et al. 2002). We calculated iF as $\left(\Sigma C_{i} \times P_{i}\right) \times$ $(B R / Q)$, where $C_{i}$ is the marginal concentration in grid cell $i$ (micrograms per cubic meter) associated with source emission rate $Q$ (micrograms per day, noting that $Q$ can be the same pollutant as $C$ or a precursor to $C$ ), $P_{i}$ is the population count in the grid cell, and $B R$ is a nominal breathing rate of $20 \mathrm{~m}^{3} /$ day. We calculated iFs for primary PM as well as secondary PM associated with various particle precursors $\left(\mathrm{SO}_{2}, \mathrm{NO}_{\mathrm{x}}, \mathrm{VOCs}\right)$ and ozone (defined as the mass of ozone inhaled per unit mass of $\mathrm{NO}_{\mathrm{x}}$ or VOC emissions). Because numerous particle constituents are influenced by precursor emission changes in CMAQ, we did not focus on $\mathrm{iF}$ values for individual constituents but discuss the dominant constituents for all secondary PM iFs. In addition, because emissions of multiple pollutants can influence $\mathrm{PM}_{2.5}$ and ozone concentrations, we estimated the pollutantspecific and sector-specific iFs by comparing the population exposures among scenarios.

Health effects. Although detailed characterization of health risks is beyond the scope of our investigation, we developed C-R functions for $\mathrm{PM}_{2.5}$ and ozone mortality to allow our CMAQ outputs to be integrated into a common metric and to allow for initial evaluation of the magnitude of health benefits, the dominant pollutants, and the key uncertainties. For both $\mathrm{PM}_{2.5}$ and ozone, we determined a central estimate, plausible lower bound, and plausible upper bound. These are not meant as formal $95 \%$ CIs but were used to construct uncertainty distributions when combining $\mathrm{PM}_{2.5}$ and ozone health benefit estimates.

As a general point, there are multiple limitations in applying C-R functions largely derived from the United States or Europe to China. There are differences in baseline disease patterns and age distributions, health care systems, pollutant levels and composition, and exposure modifiers. There are also complexities given the more recent focus on $\mathrm{PM}_{2.5}$ in U.S. and European studies but the use of $\mathrm{PM}_{10}$ or TSP in China given available monitoring data. To develop applicable C-R functions, we used a combination of evidence from the global literature and the Chinese literature.

First we considered PM: Two studies that developed C-R functions applicable to China (Aunan and Pan 2004; Levy and Greco 2007) concluded that the Chinese time-series mortality literature yielded estimates on the order of $0.3-0.4 \%$ increases in all-cause mortality per $10-\mu \mathrm{g} / \mathrm{m}^{3}$ increase in daily $\mathrm{PM}_{10}$ concentrations, slightly lower than the global literature. In a recent study that examined three cities in China (Wuhan, Shanghai, and Hong Kong), Wong et al. (2008) found a pooled C-R function for time-series mortality of $0.37 \%$ (95\% CI, $0.21-0.54 \%)$, similar to the values reported above. C-R functions in China were higher for cardiovascular and respiratory mortality, with patterns similar to those seen in the global literature.

However, health risk assessments for PM generally apply evidence from cohort mortality studies (National Research Council 2002; World Health Organization 2000), given the strength of available studies and supporting evidence for mortality risks from long-term exposure (e.g., evidence that PM contributes to accelerated atherosclerosis; Floyd et al. 2009). Recent syntheses of the cohort mortality literature (Levy et al. 2009) and expert elicitation studies (Industrial Economics 2006) found that a $1 \%$ increase in mortality per $1-\mu \mathrm{g} / \mathrm{m}^{3}$ increase in annual $\mathrm{PM}_{2.5}$ concentrations was a reasonable central estimate, falling between estimates from the Harvard Six Cities Study (Laden et al. 2006; Schwartz et al. 2008) and the American Cancer Society study (Jerrett et al. 2009; Pope et al. 2002). There is no cohort mortality evidence available in China, but earlier crosssectional studies yielded C-R functions roughly comparable to those from the U.S. cohort studies (Levy and Greco 2007).

Despite the lack of Chinese cohort mortality evidence, the literature is sufficiently compelling to indicate that mortality risk due to long-term exposure would be expected, and comparisons of the time-series estimates indicate reasonable concordance between the Chinese and U.S. literature despite the large differences in ambient concentrations and other factors. Thus, for our central estimate, we used a $1 \%$ increase in all-cause mortality per $1-\mu \mathrm{g} / \mathrm{m}^{3}$ increase in annual $\mathrm{PM}_{2.5}$ concentrations. For our bounds, we note that a recent study (Levy et al. 2009) used $0.3 \%$ as a lower bound and $2.0 \%$ as an upper bound, representing the median values across experts for the 5th and 95th percentiles of the uncertainty distribution in the recent expert elicitation study. We maintained this upper bound (which slightly exceeds the central estimate from the Harvard Six Cities Study) but used a lower bound of $0.1 \%$, reflecting a value similar to the time-series evidence and the uncertainties in determining a cohort mortality effect in China without direct evidence. These C-R functions were applied identically to all particle constituents, given a lack of systematic information to support quantitative differential toxicity, especially with respect to atmospheric conditions in China.

Ozone had not been characterized in previous studies developing $\mathrm{C}-\mathrm{R}$ functions for China, in part because of a lack of systematic evidence in the global literature at the time of those investigations. However, three recent meta-analyses and multicity studies (Bell et al. 
2005; Ito et al. 2005; Levy et al. 2005) found evidence of an independent ozone effect in the time-series literature; ozone mortality was recently evaluated in multiple Chinese cities (Wong et al. 2008), and recent evidence from the American Cancer Society cohort study (Jerrett et al. 2009) provides some indication of a long-term ozone effect on respiratory mortality. Thus, ozone mortality merits inclusion in our investigation.

Using standard units conversions and an assumption of an approximate 3:4 ratio between 8 -hr maximum and 1 -hr maximum concentrations (Levy et al. 2005), the three meta-analyses (Bell et al. 2005; Ito et al. 2005; Levy et al. 2005) yield C-R functions for all-cause mortality of $0.21 \%(95 \% \mathrm{CI}$, 0.15-0.32\%), 0.27\% (95\% CI, 0.18-0.35\%), and $0.28 \%(95 \% \mathrm{CI}, 0.21-0.35 \%)$, respectively, per $10-\mu \mathrm{g} / \mathrm{m}^{3}$ increase in 8 -hr maximum ozone. The recent multicity study in Asia (Wong et al. 2008) found that, for the three Chinese cities combined, the C-R function for all-cause mortality was $0.31 \%(95 \%$ CI, 0.13-0.48\%). Central estimates were very similar for cardiovascular and respiratory mortality $(0.29 \%$ and $0.23 \%$, respectively, although both estimates lacked statistical significance), and the all-cause mortality estimate for Shanghai is identical to the three-city pooled estimate. As for PM, little evidence exists that the ozone time-series mortality C-R function differs systematically between the Chinese cities and the global literature.

Similar to $\mathrm{PM}_{2.5}$, there is no evidence of ozone cohort mortality for China. In the U.S. cohort literature, an ozone effect on mortality was significant in one recent publication (Jerrett et al. 2009), but only for respiratory mortality in models including $\mathrm{PM}_{2.5}$. The C-R function for respiratory mortality corresponded to a $2.7 \%$ increase per $10-\mu \mathrm{g} / \mathrm{m}^{3}$ increase in 8-hr maximum ozone following the conversions above. This is significantly greater than the time-series estimates (albeit for respiratory mortality, only a fraction of all-cause mortality), but because of the lack of an impact for all-cause mortality or corroboration from other studies, we do not use this evidence for our primary $\mathrm{C}-\mathrm{R}$ functions.

Combining this evidence, we considered $0.3 \%$ reduction in all-cause mortality per $10-\mu \mathrm{g} / \mathrm{m}^{3}$ reduction in 8 - $\mathrm{hr}$ maximum ozone as a reasonable central estimate (reflecting

Table 2. Estimated emission rates by sector and pollutant in the base-case scenario for the YRD domain (thousands of tons per year).

\begin{tabular}{lrrrr}
\hline Pollutant & Industry & Power & & \\
plant & Domestic & Mobile \\
\hline $\mathrm{NO}_{\mathrm{x}}$ & 479 & 714 & 73 & 415 \\
$\mathrm{VOC}$ & 1,492 & 198 & 1,121 & 1,019 \\
$\mathrm{SO}_{2}$ & 816 & 1,464 & 71 & 11 \\
Primary $\mathrm{PM}_{2.5}$ & 571 & 115 & 231 & 30 \\
\hline
\end{tabular}

the Chinese three-city study and two of the meta-analyses), with $0.15 \%$ as a lower bound (reflecting the lower confidence limits of the various studies) and $0.45 \%$ as an upper bound (reflecting the upper confidence limit of the Chinese three-city study as well as modest weight on the emerging cohort mortality evidence).

Health benefit estimation. Although we did not develop the upper and lower bound $\mathrm{C}-\mathrm{R}$ functions as specific percentiles of uncertainty distributions, we wished to estimate net health benefits across $\mathrm{PM}_{2.5}$ and ozone, necessitating some combination of distributions. To approximate the overall net mortality change considering the uncertainty in C-R functions, we assumed that the $\mathrm{C}-\mathrm{R}$ functions for $\mathrm{PM}_{2.5}$ and ozone each follows a triangular distribution with central estimate as the mode and the lower and upper bounds as the minimum and maximum values for the distribution. We performed Monte Carlo analysis using SAS 9.1 (SAS Institute Inc., Cary, NC, USA) to combine the distributions, noting that uncertainty in other risk assessment components was not considered.

\section{Results}

Comparison between CMAQ modeling and monitoring data. To validate the performance of CMAQ, we compared ozone and $\mathrm{PM}_{2.5}$ modeling results in the base-case scenario with observation data for part of 2006 at four monitoring stations in Shanghai, using
U.S. EPA guidance (U.S. EPA 2007). The mean normalized bias (MNB) between model and observational data was relatively low for both daily average $\mathrm{PM}_{2.5}(0.5 \%)$ and daily maximum 8 -hr ozone $(-4.3 \%)$, indicating a lack of systematic model bias. For hourly ozone, the model underestimated concentrations somewhat, with MNB of $-25.3 \%$ and normalized mean error of $29 \%$. In general, model performance was considered adequate for our application.

Comparison between census and LandScan data. To provide validation of population counts, we compared China Census 2000 and LandScan 2007. For the $3-\mathrm{km}$ resolution YRD domain, the mean percentage difference by county was about 9\%. Supplemental Material, Figure S3 (doi:10.1289/ehp.1001991) shows the number of people in each grid cell in the YRD based on LandScan 2007 data. There was an average of 6,407 people in each grid cell with the maximum of 669,239 (in the Shanghai metropolitan area), corresponding to population densities of 712 and 74,360 people $/ \mathrm{km}^{2}$, respectively.

Base-case emissions and ambient concentrations. In Table 2, we show the estimated emission rates by sector and pollutant in the base-case scenario. Of note, emissions of many pollutants are high in the industry sector, in part due to the active manufacturing industry in the YRD and the lower penetration rate for pollution control technologies compared with the power sector.

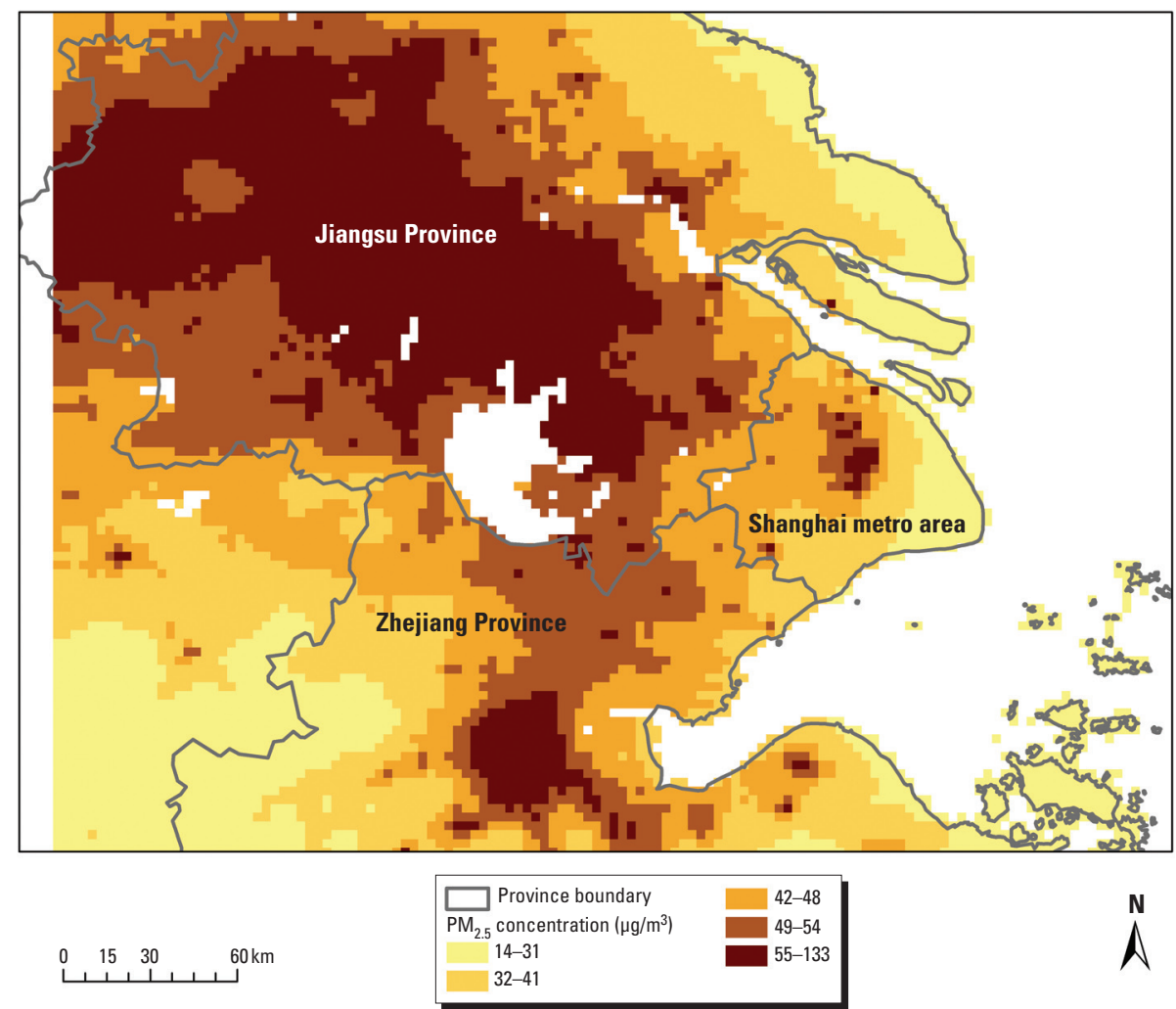

Figure 1. Estimated annual average $\mathrm{PM}_{2.5}$ concentration $\left(\mu \mathrm{g} / \mathrm{m}^{3}\right)$ in the $\mathrm{YRD}$ domain in the base-case scenario. 
Figure 1 shows the annual average $\mathrm{PM}_{2.5}$ concentration in the YRD domain in the base-case scenario. The estimated mean annual $\mathrm{PM}_{2.5}$ concentration in the YRD domain was $38.4 \mu \mathrm{g} / \mathrm{m}^{3}$, although with significant variation across the study domain (range, 12.7-132.8 $\mu \mathrm{g} / \mathrm{m}^{3}$ ). Similarly, Figure S4 in Supplemental Material (doi:10.1289/ehp.1001991) shows the annual average 8-hr maximum ozone concentration, which ranged from 17 to $54 \mathrm{ppb}$.

$i F$ variation by pollutant and sector. To estimate the pollutant-specific iFs, we compared the population exposures among scenarios (Table 3). iFs ranged significantly across pollutants, with more modest differences across sectors. Primary $\mathrm{PM}_{2.5}$ from the industry and mobile source sectors have the highest iF of $1.4 \times 10^{-5}$, which means that for every metric ton of primary $\mathrm{PM}_{2.5}$ emitted from either sector, $14 \mathrm{~g}$ is eventually inhaled by the total population in the YRD domain. For secondary $\mathrm{PM}_{2.5}$, the iF was greatest for $\mathrm{SO}_{2}$ emissions from the power sector, with a value of $1.2 \times 10^{-6}$. Among the different species of $\mathrm{PM}_{2.5}$ modeled by CMAQ, 98\% of the $\mathrm{PM}_{2.5}$ concentration reduction was attributable to sulfate and ammonium particles. For secondary $\mathrm{PM}_{2.5}$ from $\mathrm{NO}_{\mathrm{x}}$ emissions, the iFs from power plants, mobile sources, and industry are nearly identical $\left(-3.9 \times 10^{-7}\right)$. In each case, the

concentration reduction was driven by nitrate and ammonium reductions with an offsetting increase in sulfate $35 \%$ of the magnitude of the nitrate and ammonium reductions for the power sector, $20 \%$ for mobile sources, and $19 \%$ for industry). In contrast, the domestic emissions sector has a negative iF for secondary $\mathrm{PM}_{2.5}$ from $\mathrm{NO}_{\mathrm{x}}$ emissions, potentially attributable to two factors. The low $\mathrm{NO}_{\mathrm{x}}$ emissions within the domestic sector translated into a small reduction in secondary nitrate population exposure. Second, when compared with other scenarios, the domestic sector had the greatest increase in ozone concentrations per unit $\mathrm{NO}_{\mathrm{x}}$ emission reductions, which contributed to greater oxidizing power of the atmospheric and subsequent increases in other $\mathrm{PM}_{2.5}$ species (e.g., secondary sulfate and secondary organic aerosols). As a result, there is an increase in overall $\mathrm{PM}_{2.5}$ concentration corresponding to the $\mathrm{NO}_{\mathrm{x}}$ emission reductions within the domestic sector.

Across all scenarios, reducing $\mathrm{NO}_{\mathrm{x}}$ emissions alone led to an increase in ozone population exposure (as indicated by the negative values in Table 3, "Ozone from $\mathrm{NO}_{\mathrm{x}}$ "). However, when VOC emissions are reduced alone, ozone population exposures are reduced and the $\mathrm{iF}$ is on the order of $1 \times 10^{-6}$ (as shown in Table 3, "Ozone from VOC"). This

Table 3. iFs for primary $\mathrm{PM}_{2.5}$, secondary $\mathrm{PM}_{2.5}$, and 8-hr maximum ozone by emissions sector.

\begin{tabular}{|c|c|c|c|c|c|c|c|c|}
\hline \multirow[b]{2}{*}{ Sector } & \multicolumn{2}{|c|}{ Power } & \multicolumn{2}{|c|}{ Mobile } & \multicolumn{2}{|c|}{ Industry } & \multicolumn{2}{|c|}{ Domestic } \\
\hline & if & $\begin{array}{l}\text { Scenarios } \\
\text { compared }\end{array}$ & iF & $\begin{array}{l}\text { Scenarios } \\
\text { compared }\end{array}$ & iF & $\begin{array}{l}\text { Scenarios } \\
\text { compared }\end{array}$ & if & $\begin{array}{l}\text { Scenarios } \\
\text { compared }\end{array}$ \\
\hline Primary $\mathrm{PM}_{2.5}$ & & & $1.4 \times 10^{-5}$ & $5,4,3$ & $1.4 \times 10^{-5}$ & $9,8,7$ & & \\
\hline $\begin{array}{l}\text { Secondary } \mathrm{PM}_{2.5} \\
\text { From } \mathrm{SO}_{2}\end{array}$ & $1.2 \times 10^{-6}$ & 2,1 & & & & & & \\
\hline $\begin{array}{l}\text { From } \mathrm{NO}_{\mathrm{x}} \\
\text { From VOC }\end{array}$ & $3.9 \times 10^{-7}$ & 1 & $\begin{array}{l}3.9 \times 10^{-7} \\
2.4 \times 10^{-7}\end{array}$ & $\begin{array}{l}3 \\
4\end{array}$ & $\begin{array}{l}3.9 \times 10^{-7} \\
1.3 \times 10^{-7}\end{array}$ & $\begin{array}{l}7 \\
8\end{array}$ & $-2.1 \times 10^{-7}$ & 10 \\
\hline Ozone & & & & & & & & \\
\hline $\begin{array}{l}\text { From } \mathrm{NO}_{\mathrm{x}} \\
\text { From VOC }\end{array}$ & $-6.8 \times 10^{-7}$ & 1 & $\begin{array}{r}-6.9 \times 10^{-7} \\
1.7 \times 10^{-6}\end{array}$ & $\begin{array}{l}3 \\
4\end{array}$ & $\begin{array}{r}-6.9 \times 10^{-7} \\
1.4 \times 10^{-6}\end{array}$ & $\begin{array}{l}7 \\
8\end{array}$ & $-1.5 \times 10^{-5}$ & 10 \\
\hline
\end{tabular}

Blank cells indicate values not estimated in any scenario runs. if results reported are unitless. To calculate pollutantspecific iFs, we compared population exposures among scenarios, where each number is the difference between the scenario and the baseline scenario. For example, 1 means the corresponding if is calculated based on the population exposure difference between the baseline scenario and scenario 1. When multiple scenarios are listed, iF was calculated based on the difference between each scenario listed and the baseline case, as well as the difference among the scenarios listed.

Table 4. Mortality change estimates for control scenarios by sector and pollutant.

\begin{tabular}{|c|c|c|c|c|c|c|c|}
\hline Scenario & Sector & $\begin{array}{l}\text { Pollutant } \\
\text { controlled }\end{array}$ & $\begin{array}{l}\text { Emission reductions } \\
\text { from base-case } \\
\text { (1,000 tons/year) }\end{array}$ & $\begin{array}{l}\text { PM-related mortality } \\
\text { change per year }\end{array}$ & $\begin{array}{l}\text { Ozone-related mortality } \\
\text { change per year }\end{array}$ & $\begin{array}{l}\text { Net mortality change } \\
\text { (PM and ozone) } \\
\text { per year }\end{array}$ & $\begin{array}{c}\text { Net mortality change } \\
\text { per year per ton } \\
\text { of emissions }\end{array}$ \\
\hline 1 & Power & $\mathrm{NO}_{\mathrm{x}}$ & 610 & $2,000(200,4,000)$ & $-420(-210,-630)$ & $1,600(350,2,900)$ & $2.7 \times 10^{-3}$ \\
\hline 2 & Power & $\mathrm{SO}_{2}$ & 1,300 & $12,000(1,200,24,000)$ & 0 & $12,000(1,200,24,000)$ & $9.2 \times 10^{-3}$ \\
\hline 3 & Mobile & $\mathrm{NO}_{\mathrm{x}}$ & 83 & $260(26,520)$ & $-60(-30,-90)$ & $210(41,380)$ & $2.5 \times 10^{-3}$ \\
\hline 4 & Mobile & VOC & 200 & $380(38,750)$ & $38(19,57)$ & $430(190,680)$ & $2.1 \times 10^{-3}$ \\
\hline 5 & Mobile & Primary PM & 6 & $620(62,1,200)$ & 0 & $620(62,1,200)$ & $1.0 \times 10^{-1}$ \\
\hline 7 & Industry & $\mathrm{NO}_{\mathrm{x}}$ & 96 & $300(30,610)$ & $-66(-33,-99)$ & $250(51,450)$ & $2.6 \times 10^{-3}$ \\
\hline 8 & Industry & VOC & 300 & $310(31,610)$ & $45(22,67)$ & $360(160,570)$ & $1.2 \times 10^{-3}$ \\
\hline 9 & Industry & Primary PM & 110 & $12,000(1,200,24,000)$ & 0 & $12,000(1,200,24,000)$ & $1.1 \times 10^{-1}$ \\
\hline 10 & Domestic & $\mathrm{NO}_{\mathrm{x}}$ & 15 & $-21(-2,-42)$ & $-22(-11,-33)$ & $-44(-59,-29)$ & $-3.0 \times 10^{-3}$ \\
\hline
\end{tabular}

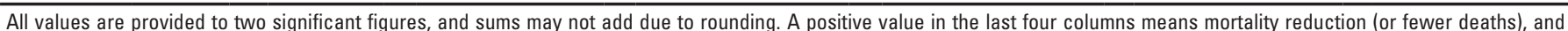

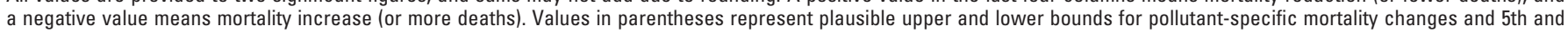

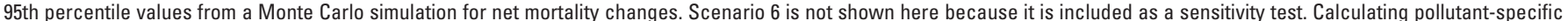

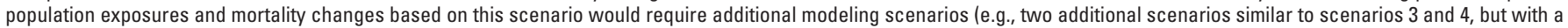
reduction percentage of $50 \%$, respectively). 
consider - the population exposure reduction per unit emission reduction and the amount of emissions that can be reduced from different sectors. As expected and shown in prior studies in China (Zhou et al. 2003, 2006), the highest population exposure reduction per unit emission reduction for $\mathrm{PM}_{2.5}$ is from controlling primary $\mathrm{PM}_{2.5}$ emissions rather than particle precursors. Because of the relatively high primary $\mathrm{PM}_{2.5}$ emissions in the industry sector and the feasibility of emissions reductions, the potential health benefits are substantial.

Considering particle precursors, $\mathrm{SO}_{2}$ emission reductions yielded greater $\mathrm{PM}_{2.5}$ exposure reductions than did $\mathrm{NO}_{\mathrm{x}}$ or $\mathrm{VOC}$ emissions reductions. In contrast, previous studies in China (Zhou et al. 2006) found similar iFs for sulfate from $\mathrm{SO}_{2}$ and nitrate from $\mathrm{NO}_{\mathrm{x}}$, both on the order of $10^{-6}$. In particular, the iFs for nitrate $\mathrm{PM}_{2.5}$ formed from $\mathrm{NO}_{\mathrm{x}}$ emissions from power plants in Shanghai and the provinces of Jiangsu and Zhejiang ranged from 2 to $5 \times 10^{-6}$, versus $4 \times 10^{-7}$ in the present study. The differences are likely due to two factors: The modeling domain in the previous study covers all of China, and the previous study used an atmospheric model (CALPUFF) that did not capture the offsetting increase in sulfate when $\mathrm{NO}_{\mathrm{x}}$ emissions are reduced.

For ozone-related health benefits, our results show that VOC control is more effective than $\mathrm{NO}_{\mathrm{x}}$ control, due to the YRD area being hydrocarbon limited in ozone formation, where ozone concentrations increase with increasing hydrocarbons (e.g., VOC) and decrease with increasing $\mathrm{NO}_{\mathrm{x}}$ (Jacob 1999). One previous study (Wang et al. 2005) found that in the Pearl River Delta area of China, urban areas are VOC limited in ozone formation and the nonurban areas are $\mathrm{NO}_{\mathrm{x}}$ limited, where ozone concentrations increase with increasing $\mathrm{NO}_{\mathrm{x}}$ and are insensitive to hydrocarbons. Our study shows that the YRD as a whole (which contains many dense urban areas) is hydrocarbon limited, although it was beyond the scope of our study to explore the implications of source controls in different regions of the YRD or the potential longrange ozone formation that could occur from $\mathrm{NO}_{\mathrm{x}}$ controls. Despite the hydrocarbonlimited ozone formation in the YRD and the relatively low particle formation per unit $\mathrm{NO}_{\mathrm{x}}$ emissions, $\mathrm{NO}_{\mathrm{x}}$ emission reductions in power, industry, and traffic sectors are net beneficial, across the range of $\mathrm{C}-\mathrm{R}$ functions simulated for ozone and $\mathrm{PM}_{2.5}$.

Limitations. Several limitations could potentially influence the interpretation of our findings. First, in estimating the health benefits per ton of emission reductions, we implicitly assumed a linear relationship between pollutant emission reductions and population exposure reductions. There are many nonlinear processes in the atmosphere chemistry that could make this assumption faulty. However, our findings suggest that nonlinearities are limited given the emission changes in our study. For example, the emission reductions in scenario 6 were 2.5 times those of scenario 5 (e.g., $50 \%$ vs. $20 \%$ reductions of $\mathrm{NO}_{\mathrm{x}}, \mathrm{VOC}$, and $\mathrm{PM}$ from the mobile sector), and the resulting total population exposures in scenario 6 were 2.53 times greater for $\mathrm{PM}_{2.5}$ and 2.44 times greater for ozone, indicating reasonable linearity.

Second, because $\mathrm{PM}_{2.5}$ is not currently a criteria air pollutant in China and there are no publicly available ozone monitoring data, the monitoring data we had access to for model validation are all from research monitoring sites located in Shanghai, which limited our ability to validate the model performance in other parts of the YRD modeling domain. Although further validation would have been ideal, various components of the model (e.g., the original emissions inventory input, the application of CMAQ in China) have been previously evaluated and validated, increasing our confidence in our findings. The lack of available monitoring data also emphasizes the need for publicly available comprehensive information systems in order to support health risk analyses and other environmental evaluations in China.

Third, although the C-R functions leveraged a combination of epidemiological evidence from the global literature and from China, our health benefit estimates are dominated by risks from long-term $\mathrm{PM}_{2.5}$ exposure, for which there is no evidence within China. Moreover, the C-R function derived from the U.S. cohort studies would imply an extremely large mortality gradient across the YRD and between different areas of China, which is challenging to validate and interpret. That said, we did not consider it appropriate to omit cohort mortality entirely, given its biological plausibility, and no evidence exists to quantitatively deviate from the available cohort evidence. More generally, our conclusions about the relative importance of various source sectors are robust to this assumption. Our core findings therefore remain interpretable despite this large uncertainty, and we recommend that the $\mathrm{C}-\mathrm{R}$ function for $\mathrm{PM}_{2.5}$ mortality in China be reevaluated as more evidence from China becomes available.

Fourth, our analysis considers mortality only from $\mathrm{PM}_{2.5}$ and ozone. Incorporation of other impacts, including morbidity outcomes or ecological damage from acid deposition, could be potentially influential if economic valuation of mortality were lower in China relative to economic valuation of morbidity than in the United States.

\section{Conclusion}

Despite the limitations, we demonstrated in this study a systematic approach to compare the effectiveness of pollutant control strategies across different sectors in a highly exposed and highly populated region of China. The use of the state-of-the-science air quality model CMAQ and a spatially resolved emission inventory allowed us to jointly consider $\mathrm{PM}_{2.5}$ and ozone exposures for different emission reduction scenarios. Our findings indicate significant variation across pollutants in health benefits per ton of emission reduction. The public health benefits of realistic controls for $\mathrm{SO}_{2}$ emissions from the power sector and primary $\mathrm{PM}_{2.5}$ emissions from the industry sector are roughly comparable, given higher emission reductions for the former and higher population exposures per ton of the latter, with lower benefits from $\mathrm{NO}_{\mathrm{x}}$ control strategies. This is attributable in part to the hydrocarbon-limited nature of the YRD, as well as to the lower secondary $\mathrm{PM}_{2.5}$ formation per ton of $\mathrm{NO}_{\mathrm{x}}$ emissions relative to other particle precursors. Our findings, in combination with plausible emissions reduction estimates and their costs, provide the basis for prioritizing pollution control strategies in the YRD and provide a template for comparable analyses elsewhere.

\section{References}

Aunan K, Pan XC. 2004. Exposure-response functions for health effects of ambient air pollution applicable for China-a meta-analysis. Sci Total Environ 329(1-3):3-16.

Bell ML, Dominici F, Samet JM. 2005. A meta-analysis of timeseries studies of ozone and mortality with comparison to the national morbidity, mortality, and air pollution study. Epidemiology 16(4):436-445.

Bell ML, Goldberg R, Hogrefe C, Kinney PL, Knowlton K, Lynn B, et al. 2007. Climate change, ambient ozone, and health in 50 US cities. Clim Change 82(1-2):61-76.

Bell ML, Peng RD, Dominici F. 2006. The exposure-response curve for ozone and risk of mortality and the adequacy of current ozone regulations. Environ Health Perspect 114:532-536.

Bennett DH, McKone TE, Evans JS, Nazaroff WW, Margni MD, Jolliet 0, et al. 2002. Defining intake fraction. Environ Sci Technol 36(9):206A-211A.

Chen CH, Wang BY, Fu QY, Green C, Streets DG. 2006. Reductions in emissions of local air pollutants and co-benefits of Chinese energy policy: a Shanghai case study. Energy Policy 34(6):754-762.

China Data Center. 2003. China 2000 County Population Census. Ann Arbor:University of Michigan.

Cohan DS, Boylan JW, Marmur A, Khan MN. 2007. An integrated framework for multipollutant air quality management and its application in Georgia. Environ Manag 40(4):545-554.

Dobson JE, Bright EA, Coleman PR, Durfee RC, Worley BA 2000. LandScan: a global population database for estimating populations at risk. Photogramm Eng Remote Sens 66(7):849-857.

Floyd HS, Chen LC, Vallanat B, Dreher K. 2009. Fine ambient air particulate matter exposure induces molecular alterations associated with vascular disease progression within plaques of atherosclerotic susceptible mice. Inhal Toxicol 21(5):394-403.

Fu JS, Streets DG, Jang CJ, Hao JM, He KB, Wang LT, et al. 2009. Modeling regional/urban ozone and particulate matter in Beijing, China. J Air Waste Manag Assoc 59(1):37-44.

Ho MS, Nielsen CP. 2007. Cleaning the Air: The Health and Economic Damages of Air Pollutions in China. Cambridge, MA:MIT Press.

Industrial Economics. 2006. Expanded Expert Judgment Assessment of the Concentration-Response Relationship between $\mathrm{PM}_{2.5}$ Exposure and Mortality. Cambridge, MA:Industrial Economics, Incorporated.

Ito K, De Leon SF, Lippmann M. 2005. Associations between 
ozone and daily mortality: analysis and meta-analysis. Epidemiology 16(4):446-457.

Jacob DJ. 1999. Introduction to Atmospheric Chemistry. Princeton, NJ:Princeton University Press.

Jerrett M, Burnett RT, Pope CA III, Ito K, Thurston G, Krewski D, et al. 2009. Long-term ozone exposure and mortality. N Engl J Med 360(11):1085-1095.

Kan HD, Chen BH, Chen CH, Fu QY, Chen M. 2004. An evaluation of public health impact of ambient air pollution under various energy scenarios in Shanghai, China. Atmos Environ 38(1):95-102.

Laden F, Schwartz J, Speizer FE, Dockery DW. 2006. Reduction in fine particulate air pollution and mortality: extended follow-up of the Harvard Six Cities study. Am J Respir Crit Care Med 173(6):667-672.

Levy JI, Chemerynski SM, Sarnat JA. 2005. Ozone exposure and mortality: an empiric Bayes metaregression analysis. Epidemiology 16(4):458-468.

Levy JI, Greco SL. 2007. Estimating health effects of air pollution in China: an introduction to intake fraction and the epidemiology. In: Clearing the Air: The Health and Economic Damages of Air Pollution in China (Ho MS, Nielsen CP, eds). Cambridge, MA:MIT Press, 115-142.

Levy JI, Greco SL, Melly SJ, Mukhi N. 2009. Evaluating efficiency-equality tradeoffs for mobile source control strategies in an urban area. Risk Anal 29(1):34-47.

Li J, Guttikunda SK, Carmichael GR, Streets DG, Chang YS, Fung V. 2004. Quantifying the human health benefits of curbing air pollution in Shanghai. J Environ Manage 70(1):49-62.
Loh C, Stevenson A, Weldon M, Hedley AJ. 2008. A Price Too High: The Health Impacts of Air Pollution in Southern China. Hong Kong:Civic Exchange.

National Research Council. 2002. Estimating the Public Health Benefits of Proposed Air Pollution Regulations. Washington, DC:National Academies Press.

Oak Ridge National Laboratory. 2009. LandScan 2007. Available: http://www.ornl.gov/sci/landscan/ [accessed 10 June 2009].

Pope CA III, Burnett RT, Thun MJ, Calle EE, Krewski D, Ito K, et al. 2002. Lung cancer, cardiopulmonary mortality, and long-term exposure to fine particulate air pollution. JAMA 287(9):1132-1141.

Pope CA III, Dockery DW. 2006. Health effects of fine particulate air pollution: lines that connect. J Air Waste Manage Assoc 56(6):709-742.

Schwartz J, Coull B, Laden F, Ryan L. 2008. The effect of dose and timing of dose on the association between airborne particles and survival. Environ Health Perspect 116:64-69.

Streets DG, Hedayat L, Carmichael GR, Arndt RL, Carter LD. 1999. PROFILE: Potential for advanced technology to improve air quality and human health in Shanghai. Environ Manag 23(3):279-295.

U.S. EPA. 2007. Guidance on the Use of Models and Other Analyses for Demonstrating Attainment of Air Quality Goals for Ozone, PM2.5, and Regional Haze. EPA 454/B-07-002. Research Triangle Park, NC:U.S. Environmental Protection Agency.

Wang XD, Smith KR. 1999. Secondary benefits of greenhouse gas control: health impacts in China. Environ Sci Technol 33(18):3056-3061.
Wang XM, Carmichael G, Chen DL, Tang YH, Wang TJ. 2005. Impacts of different emission sources on air quality during March 2001 in the Pearl River Delta (PRD) region. Atmos Environ 39(29):5227-5241.

Wang XP, Mauzerall DL. 2006. Evaluating impacts of air pollution in China on public health: implications for future air pollution and energy policies. Atmos Environ 40(9):1706-1721.

Wong CM, Vichit-Vadakan N, Kan H, Qian Z. 2008. Public Health and Air Pollution in Asia (PAPA): a multicity study of short-term effects of air pollution on mortality. Environ Health Perspect 116:1195-1202.

World Bank. 1997. Clear Water, Blue Skies: China's Environment in the New Century. Washington, DC:World Bank.

World Health Organization. 2000. Quantification of the Health Effects of Exposure to Air Pollution. Bilthoven, Netherlands:WHO, European Centre for Environment and Health.

Zhang Q, Streets DG, Carmichael GR, He K, Huo H, Kannari A, et al. 2009. Asian emissions in 2006 for the NASA INTEX-B mission. Atmos Chem Phys Discuss 9(1):4081-4139.

Zhou Y, Levy JI, Evans JS, Hammitt JK. 2006. The influence of geographic location on population exposure to emissions from power plants throughout China. Environ Int 32(3):365-373.

Zhou Y, Levy JI, Hammitt JK, Evans JS. 2003. Estimating population exposure to power plant emissions using CALPUFF: a case study in Beijing, China. Atmos Environ 37(6):815-826. 